\title{
STUDY OF LOADING OF THE LOAD-BEARING STRUCTURE OF HOPPER WAGONS ON Y25 BOGIES
}

\author{
Oleksij Fomin \\ Department of Wagons and Wagonriage Facilities \\ State University of Infrastructure and Technologies \\ 9 Kyrylivska str., Kyiv, Ukraine, 04071 \\ fomin1985@ukr.net \\ Alyona Lovska \\ Department of Wagon Engineering and Product Quality \\ Ukrainian State University of Railway Transport \\ 7 Feuerbakh sq., Kharkiv, Ukraine, 61050 \\ alyonaLovskaya.vagons@gmail.com \\ Dmytro Ivanchenko \\ Department of Rolling Stock of Transport System \\ Pryazovskyi State Technical University \\ 7 Universytetska str., Mariupol, Ukraine, 87555 \\ ukrsarterps@gmail.com \\ Sergii Zinchenko \\ Department of Personnel Management and Labor Economics \\ Mariupol Institute of the Interregional Academy of Personnel Management \\ 62 Gromovoy str., Mariupol, Ukraine, 87556 \\ s-zinchenko@ukr.net \\ Václav Píštěk \\ Institute of Automotive Engineering \\ Brno University of Technology \\ 2896/2 Technická, Brno, Czech Republic, 61669 \\ pistek.v@fme.vutbr.cz
}

\section{Abstract}

To increase the efficiency of using railway transport, the possibility of using new designs of bogies, for example, Y25 under «wide gauge» wagons was considered. In order to substantiate the proposed solution, mathematical modeling of the dynamic loading of the hopper wagon Y25 bogies was carried out. A hopper wagon for the transportation of pellets and hot sinter model 20-9749 built by the State Enterprise «Ukrspetsvagon» (Ukraine) was chosen as a prototype. The simulation results showed that the use of Y25 bogies for hopper wagons allows to reduce the acceleration of its load-bearing structure, in comparison with the use of conventional 18100 bogies, by $36 \%$. Other performance indicators are also significantly improved.

The use of Y25 bogies for hopper wagons with actual parameters allows to reduce the acceleration of its load-bearing structure, in comparison with the use of conventional 18100 bogies, by $28 \%$.

The determination of the main indicators of the strength of the bearing structure of the hopper wagon Y25 bogie was carried out. The calculation was carried out in the SolidWorks Simulation software package (CosmosWorks), (France), which implements the finite element method. The calculations showed that the maximum equivalent stresses in the load-bearing structure of a hopper wagon with nominal parameters are $17 \%$ lower than the stress acting in the load-bearing structure of a wagon on bogies $18-100 \mathrm{~V}$ of the load-bearing structure of a hopper wagon with actual parameters, the maximum equivalent stresses are $12 \%$ lower per voltage in the load-bearing structure on bogies 18100 .

The conducted research will help to reduce the load on the load-bearing structures of hopper wagons in operation, improve the dynamics and strength indicators, as well as their service life.

Keywords: transport mechanics, hopper wagon, load-bearing structure, bogie, dynamic load, load simulation. 


\section{Introduction}

The prospects for the technical and economic development of European countries, as well as the strengthening of their external relations, determine an increase in the efficiency of the operation of railway rolling stock, as a leading branch of the transport system. For the competitiveness of railway rolling stock at the present stage of development of the transport industry, it is important to put into operation a highly efficient innovative rolling stock. At the same time, considerable attention should be paid to its driving performance. It is these indicators that determine the speed of delivery of goods, traffic safety, strength and reliability of constituent structures, etc.

In this regard, in order to increase the efficiency of the transportation process, it is necessary to put into operation bogies with improved dynamic performance, as an alternative version of the 18-100 bogies, which has been operated on broad-gauge railways since the $50 \mathrm{~s}$ of the last century.

Analysis of modern designs of rolling stock bogies allowed to conclude that one of the most promising is the European bogie model Y25 (Fig. 1).

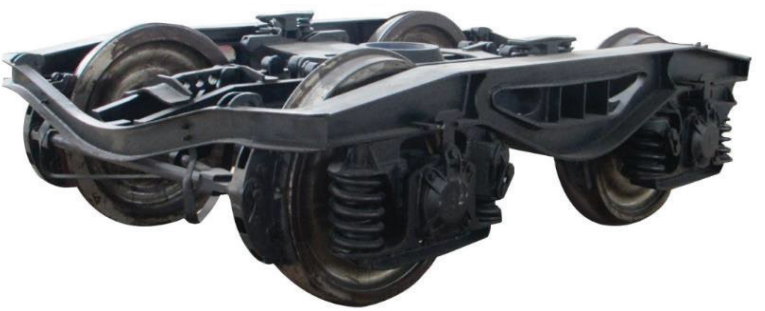

Fig. 1. Y25 bogie model

The load-bearing structure of the bogie is a closed-configuration frame, which is made by stamping-welded method. Suspension springs, one-stage, over-axle with a friction wedge vibration damper. The bogie frame is supported by double-row cylindrical springs on the bosses of the axle box bodies. The body of the axle box is located in the jaw opening and has restrictions on vertical movement. The bogie is equipped with permanent contact side sliders.

To improve the dynamic performance of wagons, it is advisable to study their loading when using Y25 bogies.

Features of the study of the dynamic loading of a wagon on various types of bogies are described in [1]. At the same time, the emphasis is on the advanced designs of LEILA and SUSTRAIL bogies. The main indicators of the wagon dynamics were determined.

A comparative study of the dynamic interaction of wheels with rails when using bogies with lateral frame cross-braces and a radial subframe bogie is carried out in [2]. It was found that the radial bogie of the subframe has the best characteristics of wheel-rail interaction.

It is important to say that the research did not take into account the actual geometric parameters of the load-bearing elements of the bogie structures. This can contribute to the occurrence of a certain error in the calculations.

Determination of the dynamic and strength characteristics of the new design cargo bogie is carried out in [3]. In this case, the cart consists of two auxiliary parts, connected by diagonal rods.

The influence of the components of stiffness and damping of the main and auxiliary suspension of the bogie on the dynamic characteristics of a high-speed train is investigated in [4]. For the analysis, a model of a railway bogie was selected on two levels of suspension: symmetric and asymmetric configuration.

However, in the studies considered, no attention was paid to determining the influence of dynamic loads acting on the load-bearing structure of the wagon when using the considered bogie structures.

The structural analysis of a modified freight wagon was carried out in [5]. The studies were carried out by FE methods. The calculation results confirmed the feasibility of the adopted technical solutions.

The features of modeling a multi-body system of a freight wagon, as well as its dynamic properties by computational modeling are highlighted in [6]. The research was carried out on Y25 bogie. 
At the same time, the determination of the influence of the Y25 bogie on the dynamic loading of the load-bearing structure of a freight wagon is not carried out in these works.

In works $[7,8]$, measures are proposed to reduce the dynamic loading of the load-bearing structures of wagons during operating conditions. Justification of the proposed solutions was carried out by means of mathematical modeling and confirmed by computer.

However, the authors did not conduct research on the use of bogies with optimal characteristics of spring suspension to reduce the dynamic loading of the load-bearing structures of the wagons.

The conducted literature review allows to conclude that the issue of determining the dynamic loading of the load-bearing structures of wide-gauge wagons on Y25 bogies has not yet been covered. This requires appropriate research in this direction.

The aim of research is to highlight the features of the dynamic loading of the load-bearing structure of the hopper wagon on the Y25 bogies. To achieve this aim, the following objectives have been identified:

- to carry out mathematical modeling of the dynamic loading of the load-bearing structure of a hopper wagon with nominal parameters;

- to carry out mathematical modeling of the dynamic loading of the bearing structure of the hopper wagon with the actual parameters;

- to determine the strength indicators of the load-bearing structure of the hopper wagon.

\section{Materials and methods}

To determine the main indicators of the dynamics of the bearing structure of the hopper wagon on the Y25 bogies, mathematical modeling was carried out. In this case, the mathematical model presented in [9] was used. Attention was given to the accepted vibrations of the bogie load-bearing structure in the vertical plane - bouncing vibrations, as one of the most common types of bogie vibrations in operation.

It was taken into account that the wagon is moving in an empty state, since in this case its most dynamic load is observed when moving with butt inequality. The track was considered as elastic-viscous. Path reactions were proportional to both its deformation and the rate of this deformation. The design scheme is shown in Fig. 2.

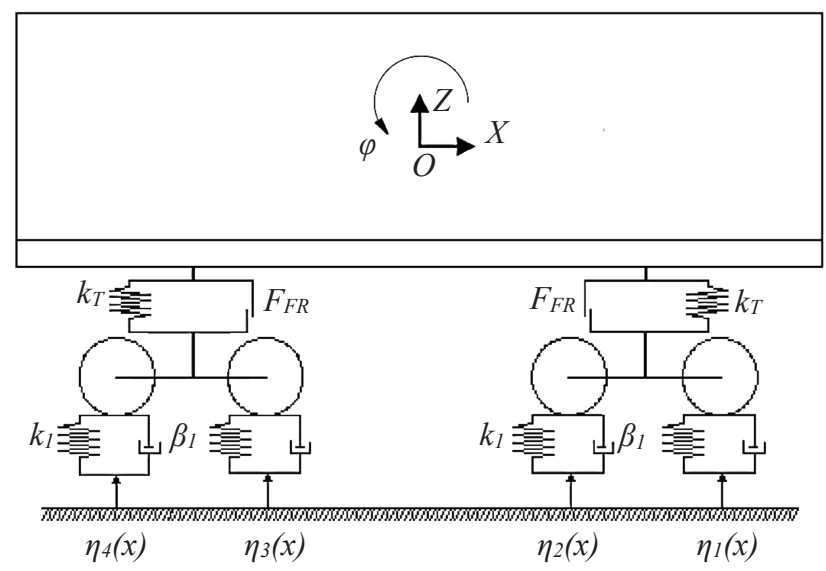

Fig. 2. Design scheme of the wagon

The equations of motion of the design model are as follows:

$$
\begin{gathered}
M_{1} \cdot \frac{d^{2}}{d t^{2}} q_{1}+C_{1,1} \cdot q_{1}+C_{1,3} \cdot q_{3}+C_{1,5} \cdot q_{5}=F_{z}, \\
M_{2} \cdot \frac{d^{2}}{d t^{2}} q_{2}+C_{2,2} \cdot q_{2}+C_{2,3} \cdot q_{3}+C_{2,5} \cdot q_{5}=F_{\varphi},
\end{gathered}
$$




$$
\begin{gathered}
M_{3} \cdot \frac{d^{2}}{d t^{2}} q_{3}+C_{3,1} \cdot q_{1}+C_{3,2} \cdot q_{2}+C_{3,3} \cdot q_{3}+B_{3,3} \cdot \frac{d}{d t} q_{3}=F_{z}^{B 1}, \\
M_{4} \cdot \frac{d^{2}}{d t^{2}} q_{4}+C_{4,4} \cdot q_{4}+B_{4,4} \cdot \frac{d}{d t} q_{4}=F_{\varphi}^{B 1} \\
M_{5} \cdot \frac{d^{2}}{d t^{2}} q_{5}+C_{5,1} \cdot q_{1}+C_{5,2} \cdot q_{2}+C_{5,5} \cdot q_{5}+B_{5,5} \cdot \frac{d}{d t} q_{5}=F_{z}^{B 2}, \\
M_{6} \cdot \frac{d^{2}}{d t^{2}} q_{6}+C_{6,6} \cdot q_{6}+B_{6,6} \cdot \frac{d}{d t} q_{6}=F_{\varphi}^{B 2}, \\
F_{z}=-F_{F R} \cdot\left(\operatorname{sign}\left(\frac{d}{d t} \delta_{1}\right)+\operatorname{sign}\left(\frac{d}{d t} \delta_{2}\right)\right) \\
F_{\varphi}=F_{F R} \cdot l \cdot\left(\operatorname{sign}\left(\frac{d}{d t} \delta_{1}\right)+\operatorname{sign}\left(\frac{d}{d t} \delta_{2}\right)\right) \\
F_{\varphi}^{B 2}=F_{F R} \cdot \operatorname{sign}\left(\frac{d}{d t} \delta_{2}\right)+k_{1}\left(\eta_{3}+\eta_{4}\right)+\beta_{1}\left(\frac{d}{d t} \eta_{3}+\frac{d}{d t} \eta_{4}\right) \\
F_{F R} \cdot \operatorname{sign}\left(\frac{d}{d t} \delta_{1}\right)+k_{1}\left(\eta_{1}+\eta_{2}\right)+\beta_{1}\left(\frac{d}{d t} \eta_{1}+\frac{d}{d t} \eta_{2}\right) \\
\left.F_{1}-\eta_{2}\right)-\beta_{1} \cdot a \cdot\left(\frac{d}{d t} \eta_{1}-\frac{d}{d t} \eta_{2}\right),
\end{gathered}
$$

where $M_{1}, M_{2}$ - respectively, the mass and moment of inertia of the load-bearing structure of the hopper wagon during vibrations of bouncing and galloping; $M_{3}, M_{4}$ - respectively, the mass and moment of inertia of the first bogie in the direction of movement during vibrations of jumping and galloping; $M_{5}, M_{6}$ - respectively, the mass and moment of inertia of the second bogie in the direction of movement during vibrations of jumping and galloping; $C_{i j}$ - characteristic of the elasticity of the vibrating system elements; $B_{i}$ - scattering function; $a$ - half of the bogie base; $q_{i}$ - generalized coordinates corresponding to translational displacement about the vertical axis and angular displacement around the vertical axis; $k_{i}$ - rigidity of the spring suspension; $\beta_{i}$ - damping factor; $F_{F R}$ - force of absolute friction in the spring set.

The input parameters of the model are the technical characteristics of the bogie load-bearing structure, spring suspension of bogies, as well as the disturbing action (rail inequality). The hopper wagon model 20-9749 was chosen as the examined one (Fig. 3). For a comparative analysis, calculations were also carried out relative to a wagon on 18-100 bogies.

To determine the masses and moments of inertia of the load-bearing structure of the hopper wagon, its spatial model was built in the SolidWorks software package (Fig. 4).

At the same time, the mass of the load-bearing structure of the hopper wagon with nominal dimensions was 15.6 tons, and the moment of inertia was $242.3 \mathrm{t} \cdot \mathrm{m}^{2}$. The weight of the load-bearing structure of the hopper wagon with actual dimensions was $14.1 \mathrm{t}$, and the moment of inertia was $219.8 \mathrm{t} \cdot \mathrm{m}^{2}$. So the percentage of weight reduction compared to the prototype wagon was $9.3 \%$.

To solve differential equations (1)-(6), they were reduced to the Cauchy normal form. After that, they are integrated by the Runge-Kutta method [10-12]. 


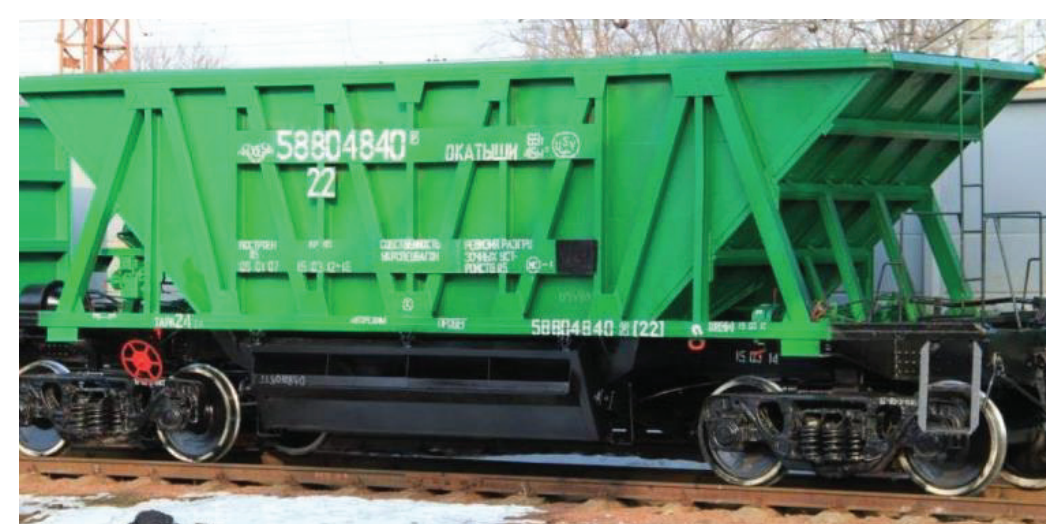

Fig. 3. The hopper wagon model 20-9749

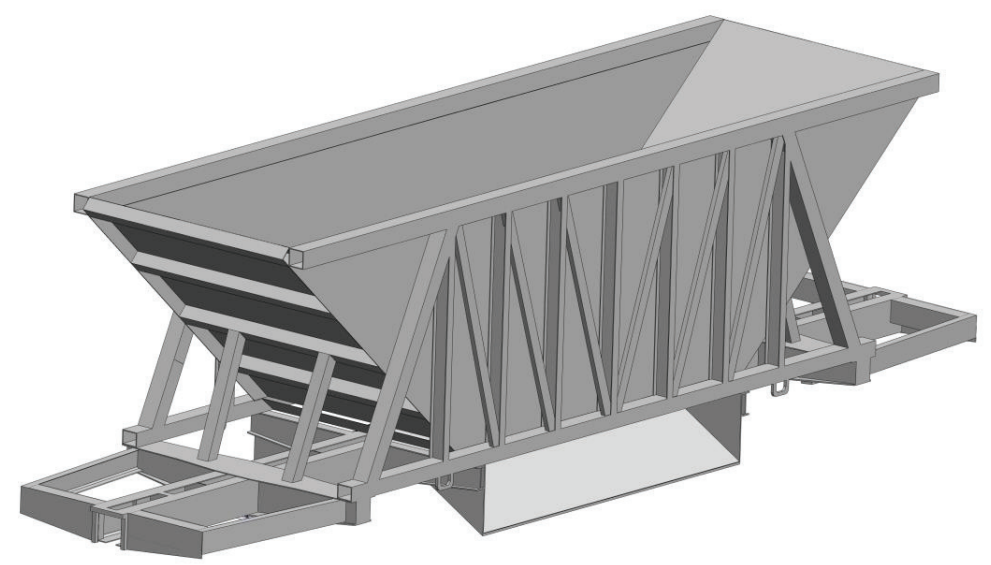

Fig. 4. Spatial model of the load-bearing structure of a hopper wagon

\section{Results of modeling the loading of the load-bearing structure of a hopper wagon}

3. 1. Results of mathematical modeling of dynamic loading of the load-bearing structure of a hopper wagon with nominal parameters

Based on the calculations, the main indicators of the dynamics of the hopper wagon on 18-100 and Y25 bogies were determined. In this case, the initial displacements and speeds are taken to be zero.

The acceleration acting on the load-bearing structure of the hopper wagon at the center of mass is shown in Fig. 5.
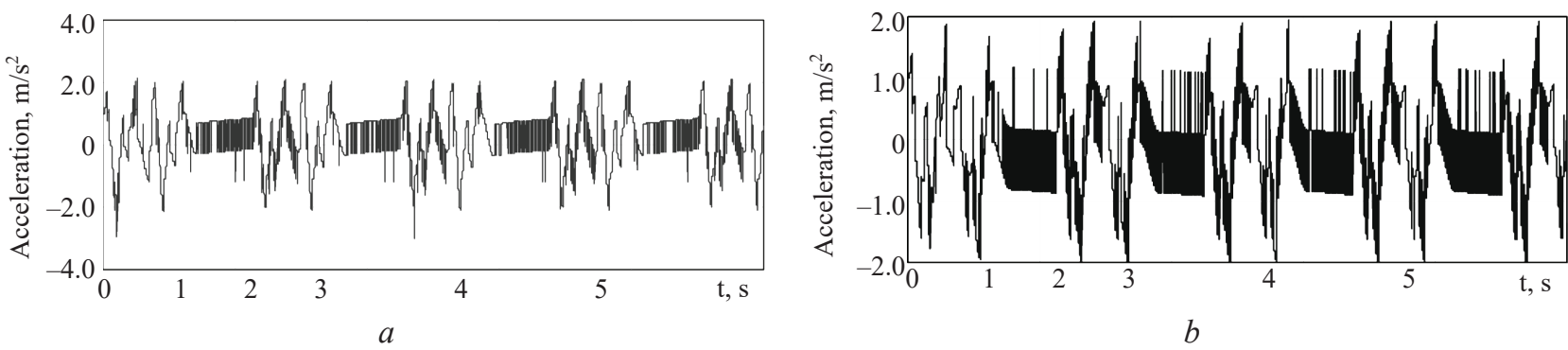

Fig. 5. Acceleration of the load-bearing structure of the hopper wagon in the center of mass:

$$
a-18-100 ; b-\mathrm{Y} 25
$$

Other indicators of the dynamics of the hopper wagon were determined by the mathematical model (1)-(6) (Table 1). The calculation was carried out at a wagon speed of $80 \mathrm{~km} / \mathrm{h}$. 
Table 1

Dynamic indicators of a hopper wagon that moves in an empty state

\begin{tabular}{lcc}
\hline \multicolumn{1}{c}{ Indicator } & \multicolumn{2}{c}{ Bogie type } \\
\cline { 2 - 4 } & $\mathbf{1 8 - 1 0 0}$ & Y25 \\
\hline Body acceleration, $\mathrm{m} / \mathrm{s}^{2}$ & 3.1 & 1.98 \\
Body acceleration in the area of support on bogies, $\mathrm{m} / \mathrm{s}^{2}$ & 4.8 & 2.7 \\
Force in the spring suspension of the bogie, $\mathrm{kN}$ & 38.3 & 23.98 \\
First bogie dynamic coefficient & 0.49 & 0.31
\end{tabular}

The results allow to conclude that the dynamics indicators are within acceptable limits. The movement of the bogie is assessed as «excellent» [13-15]. A comparative analysis of the obtained indicators of the dynamics of the hopper wagon is shown in Fig. 6.

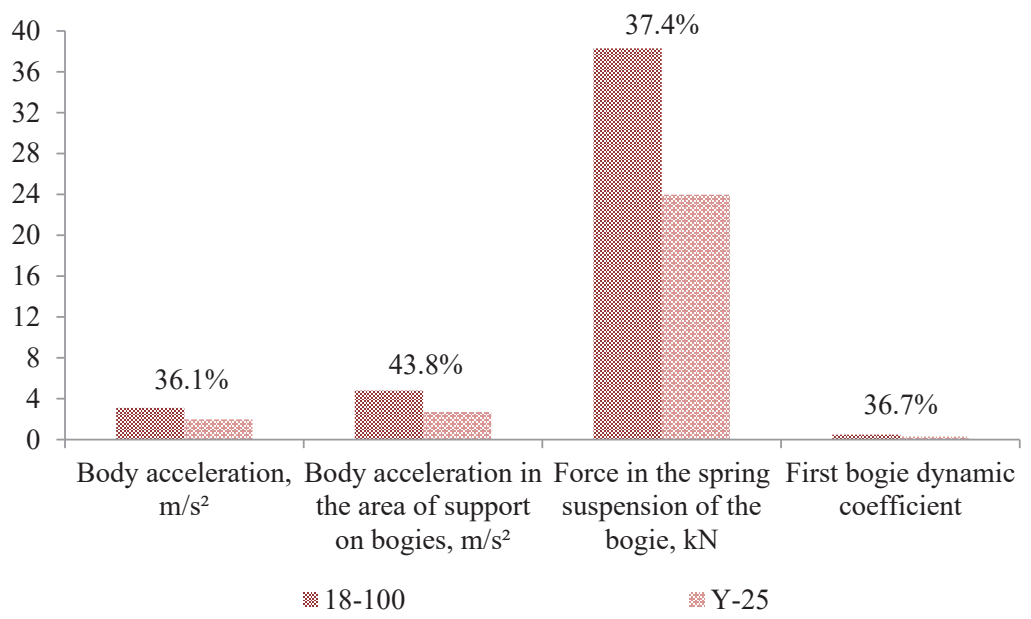

Fig. 6. Comparative analysis of indicators of the dynamics of the hopper wagon on $18-100$ and Y25 bogies

The use of Y 25 bogies for hopper wagons allows to reduce the acceleration of its load-bearing structure by $36 \%$ in comparison with conventional $18-100$ bogies. Other indicators of dynamics are also significantly improved (Fig. 6).

3. 2. Results of mathematical modeling of dynamic loading of the load-bearing structure of a hopper wagon with actual parameters

According to the mathematical model (1)-(6), the main indicators of the dynamics of the load-bearing structure of the hopper wagon with the actual parameters were determined.

The acceleration acting on the load-bearing structure of the hopper wagon at the center of mass is shown in Fig. 7.
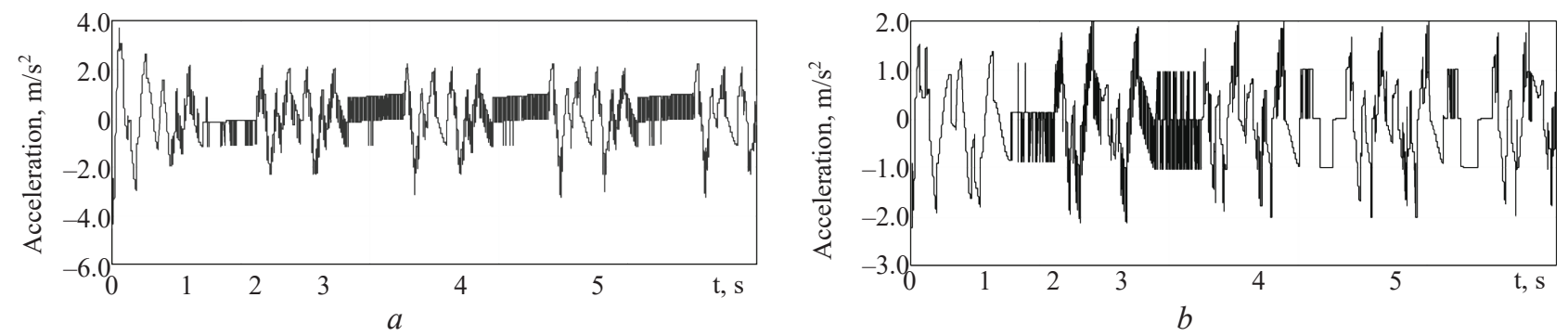

Fig. 7. Acceleration of the load-bearing structure of the hopper wagon in the center of mass:

$$
a-18-100 ; b-\mathrm{Y} 25
$$


Other indicators of the dynamics of the hopper wagon were determined by the mathematical model (1)-(6) (Table 2).

The results obtained allow to conclude that the dynamics indicators are within acceptable limits. The movement of the bogie is assessed as «excellent» [13-15]. A comparative analysis of the obtained indicators of the dynamics of the hopper wagon is shown in Fig. 8, which shows the percentage improvement of individual indicators of the wagon dynamics on Y25 bogies compared to 18-100.

Table 2

Dynamic indicators of a hopper wagon that moves in an empty state

\begin{tabular}{lcc}
\hline \multicolumn{1}{c}{ Indicator } & Bogie type & Y25 \\
\cline { 2 - 4 } & $\mathbf{1 8 - 1 0 0}$ & 2.3 \\
Body acceleration, $\mathrm{m} / \mathrm{s}^{2}$ & 3.2 & 3.38 \\
Body acceleration in the area of support on bogies, $\mathrm{m} / \mathrm{s}^{2}$ & 36.9 & 3.66 \\
Force in the spring suspension of the bogie, $\mathrm{kN}$ & 0.52 & 26.2 \\
First bogie dynamic coefficient & 0.37 &
\end{tabular}

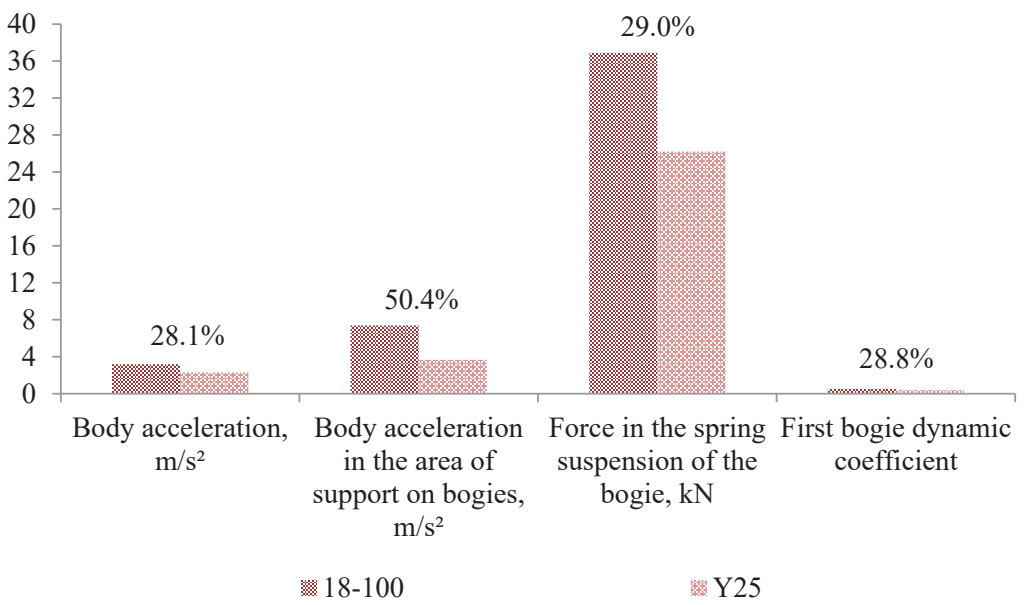

Fig. 8. Comparative analysis of the indicators of the dynamics of the hopper wagon on 18-100 and Y25 bogies

The use of Y25 bogies for hopper wagons allows to reduce the acceleration of its load-bearing structure, in comparison with conventional $18-100$ bogies, by $28 \%$. Other indicators of dynamics are also significantly improved (Fig. 8).

\section{3. Results of determining the strength indicators of the load-bearing structure of the hopper wagon}

To determine the main indicators of the strength of the load-bearing structure of the hopper wagon, taking into account the use of various types of bogies, a calculation was carried out. In this case, the finite element method was used, which is implemented in the SolidWorks Simulation (CosmosWorks) software package [16-19]. When compiling the finite element model, spatial tetrahedrons were used [20-24]. To determine the optimal number of elements, the graphic-analytical method was used [25-27]. The number of grid elements was 374 143, nodes - 125817. The maximum size of a grid element is $60 \mathrm{~mm}$, the minimum is $12 \mathrm{~mm}$, the maximum aspect ratio of elements is 432.78 , the percentage of elements with an aspect ratio of less than three is 7.71 , more than ten is 32.9 . The material of the load-bearing structure of the hopper wagon is $09 \mathrm{G} 2 \mathrm{~S}$ steel. The fixing of the model was carried out in the zones of the load-bearing structure on the bogies. The design diagram of the hopper wagon is shown in Fig. 9. It is taken into account that the load-bearing structure is acted upon by the vertical load $P_{v}$, the expansion forces of the bulk cargo $P_{e}$. The front stops of the automatic coupler are affected by the longitudinal load $P_{l}$, which is due to the driving mode [28, 29]. 
The calculations showed that the maximum equivalent stresses in the load-bearing structure of the hopper wagon with nominal parameters are concentrated in the zone of interaction of the pivot girder with the center girder and amount to $182.6 \mathrm{MPa}$ (Fig. 10). The resulting value of stresses is $17 \%$ lower than the stress acting in the load-bearing structure of the wagon on 18-100 bogies. In the bearing structure of the hopper wagon with actual parameters, the maximum equivalent stresses were 193.2 MPa, which is $12 \%$ lower in terms of stress in the bearing structure on bogies $18-100$.

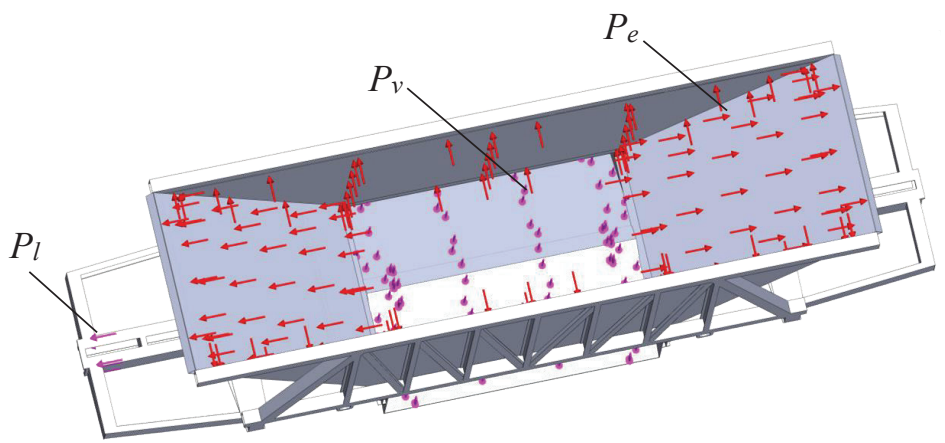

Fig. 9. Design scheme of a hopper wagon

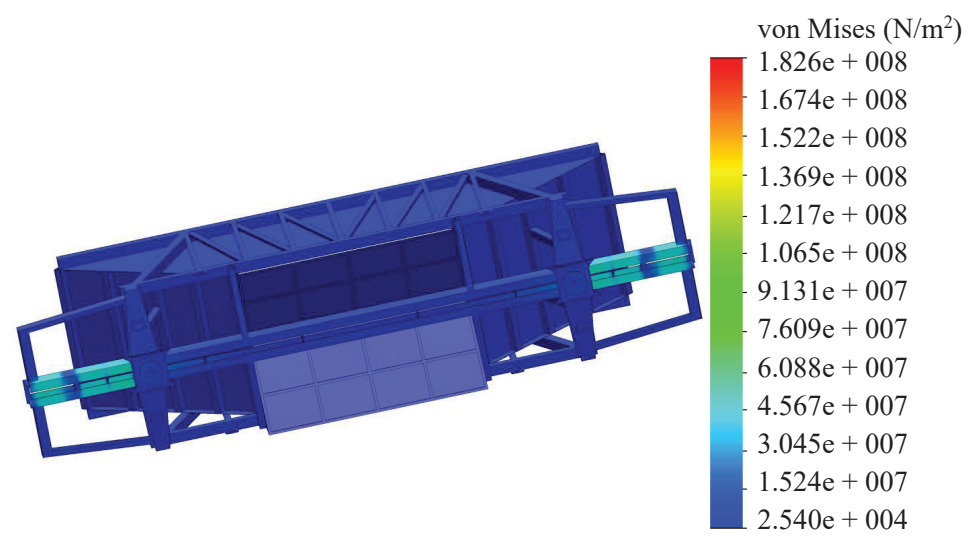

Fig. 10. Stress state of the load-bearing structure of the hopper wagon

\section{Discussion of the research results of the loading of the load-bearing structure of the hopper wagon}

The main dynamic parameters of the load-bearing structure of the hopper wagon on 18-100 and Y25 bogies were obtained. The studies were carried out for the load-bearing structure of a hopper wagon with nominal and actual parameters.

It was found that the use of Y25 bogies for hopper wagons with nominal parameters makes it possible to reduce the acceleration of its load-bearing structure, in comparison with conventional bogies $18-100$, by $36.1 \%$ (Fig. 6). Relative to the load-bearing structure of the hopper wagon with the actual parameters - the acceleration of the load-bearing structure is reduced by $28 \%$ (Fig. 8).

It is important to note that the studies were carried out in a vertical plane. That is, bouncing vibrations are considered as one of the most common types of wagon vibrations in operation. The limitation of this model is that bogie slippage relative to the rail track is taken into account when compiling it.

The maximum equivalent stresses in the load-bearing structure of the hopper wagon with nominal and actual parameters have been determined. It was found that taking into account the use of Y25 bogies, the stresses in the load-bearing structure with nominal parameters are $17 \%$ lower than the stress acting on the 18-100 bogies (Fig. 10). In the load-bearing structure of a hopper wagon with actual parameters, the maximum equivalent stresses are $12 \%$ lower than the stress in the load-bearing structure on $18-100$ bogies.

In further studies in this direction, it is necessary to study the longitudinal loading of the load-bearing structure of the hopper wagon on the Y25 bogies. It is also expedient to conduct 
an experimental determination of the dynamic loading of the load-bearing structures of hopper wagons. The results can contribute to the creation of recommendations for the creation of modern structures of rolling stock, improving the dynamics and strength of the load-bearing structures of wagons, traffic safety, safety of goods during transportation, and the like.

\section{Conclusions}

The dynamic loading of the load-bearing structure of the hopper wagon with nominal parameters on Y25 bogies was investigated. It was found that the use of Y25 bogies for hopper wagons allows to reduce the acceleration of its load-bearing structure, in comparison with conventional bogies $18-100$, by $36 \%$.

The dynamic loading of the load-bearing structure of the hopper wagon with actual parameters on the Y25 bogies was investigated. In this case, it becomes possible to reduce the acceleration of the load-bearing structure of the hopper wagon by $28 \%$ in comparison with the use of $18-100$ bogies.

The strength indicators of the load-bearing structure of the hopper wagon on the Y 25 bogies were determined. The resulting value of stresses is $17 \%$ lower than the stress acting in the load-bearing structure of the wagon on the 18-100 bogies.

In the load-bearing structure of a hopper wagon with actual parameters, the maximum equivalent stresses are $12 \%$ lower in terms of the stress in the load-bearing structure on 18-100 bogies.

The research carried out will help to reduce the load on the load-bearing structures of wagons in operation, to improve the dynamics and strength indicators, as well as the service life. Also, studies have been carried out to improve the efficiency of the operation of railway transport and the maintenance of its leadership positions in the transportation market.

\section{Acknowledgement}

This publication was made within the framework of the project «Development of conceptual frameworks for restoring the efficient operation of obsolete freight wagons». Registration number of the project: 2020.02/0122, which is financed by the National Research Fund of Ukraine from the state budget.

\section{References}

[1] Iwnicki, S. D., Stichel, S., Orlova, A., Hecht, M. (2015). Dynamics of railway freight vehicles. Vehicle System Dynamics, 53 (7), 995-1033. doi: https://doi.org/10.1080/00423114.2015.1037773

[2] Yang, C., Li, F., Huang, Y., Wang, K., He, B. (2013). Comparative study on wheel-rail dynamic interactions of side-frame cross-bracing bogie and sub-frame radial bogie. Journal of Modern Transportation, 21 (1), 1-8. doi: https://doi.org/10.1007/s40534-013-0001-3

[3] Savoskin, A., Akishin, A., Yurchenko, D. (2017). Dynamics and optimization of a new double-axle flexible bogie for highspeed trains. Proceedings of the Institution of Mechanical Engineers, Part F: Journal of Rail and Rapid Transit, 232 (5), 1549-1558. doi: https://doi.org/10.1177/0954409717737879

[4] Mousavi Bideleh, S. M., Berbyuk, V. (2016). Global sensitivity analysis of bogie dynamics with respect to suspension components. Multibody System Dynamics, 37 (2), 145-174. doi: https://doi.org/10.1007/s11044-015-9497-0

[5] Dižo, J., Harušinec, J., Blatnický, M. (2017). Structural Analysis of a Modified Freight Wagon Bogie Frame. MATEC Web of Conferences, 134, 00010. doi: https://doi.org/10.1051/matecconf/201713400010

[6] Dižo, J., Blatnický, M., Pavlík, A. (2018). Process of modelling the freight wagon multibody system and analysing its dynamic properties by means of simulation computations. MATEC Web of Conferences, 235, 00027. doi: https://doi.org/10.1051/ matecconf/201823500027

[7] Fomin, O., Lovska, A. (2020). Establishing patterns in determining the dynamics and strength of a covered freight car, which exhausted its resource. Eastern-European Journal of Enterprise Technologies, 6 (7 (108)), 21-29. doi: https:// doi.org/10.15587/1729-4061.2020.217162

[8] Fomin, O., Lovska, A. (2020). Improvements in passenger car body for higher stability of train ferry. Engineering Science and Technology, an International Journal, 23 (6), 1455-1465. doi: https://doi.org/10.1016/j.jestch.2020.08.010

[9] Domin, Yu. V., Cherniak, H. Yu. (2003). Osnovy dynamiky vahoniv. Kyiv: KUETT, 269.

[10] Lovska, A. (2018). Simulation of loads on the carrying structure of an articulated flat car in combined transportation. International Journal of Engineering \& Technology, 7 (4.3), 140-146. Available at: https://www.sciencepubco.com/index.php/ijet/ article/view/19724/9151 
[11] Fomin, O. V., Burlutsky, O. V., Fomina, Yu. V. (2015). Development and application of cataloging in structural design of freight car building. Metallurgical and Mining Industry, 2, 250-256.

[12] Lovska, A. O. (2015). Computer simulation of wagon body bearing structure dynamics during transportation by train ferry. Eastern-European Journal of Enterprise Technologies, 3 (7 (75)), 9-14. doi: https://doi.org/10.15587/1729-4061.2015.43749

[13] DSTU 7598:2014. Freight wagons. General reguirements to calculation and designing of the new and modernized $1520 \mathrm{~mm}$ gauge wagons (non-self-propelled).

[14] GOST 33211-2014. Freight wagons. Requirements to structural strength and dynamic qualities.

[15] EN 12663-2:2010. Railway applications - structural requirements of railway vehicle bodies - Part 2: Freight wagons.

[16] Kuric, I., Gorobchenko, O., Litikova, O., Gritsuk, I., Mateichyk, V., Bulgakov, M., Klackova, I. (2020). Research of vehicle control informative functioning capacity. IOP Conference Series: Materials Science and Engineering, 776, 012036. doi: https:// doi.org/10.1088/1757-899x/776/1/012036

[17] Goolak, S., Gubarevych, O., Yermolenko, E., Slobodyanyuk, M., Gorobchenko, O. (2020). Mathematical modeling of an induction motor for vehicles. Eastern-European Journal of Enterprise Technologies, 2 (2 (104)), 25-34. doi: https:// doi.org/10.15587/1729-4061.2020.199559

[18] Alyamovskiy, A. A. (2007). SolidWorks/COSMOSWorks 2006-2007. Inzhenerniy analiz metodom konechnyh elementov. Moscow, 784.

[19] Alyamovskiy, A. A. (2010). COSMOSWorks. Osnovy rascheta konstruktsiy na prochnost' v srede SolidWorks. Moscow.

[20] Vatulia, G., Komagorova, S., Pavliuchenkov, M. (2018). Optimization of the truss beam. Verification of the calculation results. MATEC Web of Conferences, 230, 02037. doi: https://oi.org/10.1051/matecconf/201823002037

[21] Vatulia, G. L., Lobiak, O. V., Deryzemlia, S. V., Verevicheva, M. A., Orel, Y. F. (2019). Rationalization of cross-sections of the composite reinforced concrete span structure of bridges with a monolithic reinforced concrete roadway slab. IOP Conference Series: Materials Science and Engineering, 664, 012014. doi: https://doi.org/10.1088/1757-899x/664/1/012014

[22] Plakhtii, O., Nerubatskyi, V., Sushko, D., Hordiienko, D., Khoruzhevskyi, H. (2020). Improving the harmonic composition of output voltage in multilevel inverters under an optimum mode of amplitude modulation. Eastern-European Journal of Enterprise Technologies, 2 (8 (104)), 17-24. doi: https://doi.org/10.15587/1729-4061.2020.200021

[23] Plakhtii, O. A., Nerubatskyi, V. P., Hordiienko, D. A., Khoruzhevskyi, H. A. (2020). Calculation of static and dynamic losses in power IGBT-transistors by polynomial approximation of basic energy characteristics. Naukovyi Visnyk Natsionalnoho Hirnychoho Universytetu, 2, 82-88. doi: https://doi.org/10.33271/nvngu/2020-82

[24] Plakhtii, O., Nerubatskyi, V., Karpenko, N., Ananieva, O., Khoruzhevskyi, H., Kavun, V. (2019). Studying a voltage stabilization algorithm in the cells of a modular sixlevel inverter. Eastern-European Journal of Enterprise Technologies, 6 (8 (102)), 19-27. doi: https://doi.org/10.15587/1729-4061.2019.185404

[25] Bychkov, A. S., Kondratiev, A. V. (2019). Criterion-Based Assessment of Performance Improvement for Aircraft Structural Parts with Thermal Spray Coatings. Journal of Superhard Materials, 41 (1), 53-59. doi: https://doi.org/10.3103/s1063457619010088

[26] Kondratiev, A., Gaidachuk, V., Nabokina, T., Tsaritsynskyi, A. (2020). New Possibilities of Creating the Efficient Dimensionally Stable Composite Honeycomb Structures for Space Applications. Advances in Intelligent Systems and Computing, 45-59. doi: https://doi.org/10.1007/978-3-030-37618-5_5

[27] Kliuiev, S. (2018). Experimental study of the method of locomotive wheelrail angle of attack control using acoustic emission. Eastern-European Journal of Enterprise Technologies, 2 (9 (92)), 69-75. doi: https://doi.org/10.15587/1729-4061.2018.122131

[28] Lukin, V. V., Shadur, L. A., Koturanov, V. I., Khokhlov, A. A., Anisimov, P. S. (2000). Konstruirovanie i raschet vagonov. Moscow: UMK MPS Rossii.

[29] Fomin, O., Lovska, A., Skliarenko, I., Klochkov, Y. (2020). Substantiating the optimization of the load-bearing structure of a hopper car for transporting pellets and hot agglomerate. Eastern-European Journal of Enterprise Technologies, 1 (7 (103)), 65-74. doi: https://doi.org/10.15587/1729-4061.2020.193408

Received date 02.12.2020

(C) The Author(s) 2021

Accepted date 08.02.2021

Published date 31.03.2021

This is an open access article under the CC BY license (http://creativecommons.org/licenses/by/4.0).

How to cite: Fomin, O., Lovska, A., Ivanchenko, D., Zinchenko, S., Píštěk, V. (2021). Study of loading of the load-bearing structure of hopper wagons on Y25 bogies. EUREKA: Physics and Engineering, 2, 32-41. doi: https://doi.org/10.21303/2461-4262.2021.001686 